\title{
EDUCACIÓN PARA EL MAÑANA: ACERCAMIENTOS FILOSÓFICOS AL PAPEL DE LA UNIVERSIDAD EN COLOMBIA PARA UNA EDUCACION EN LA MAYORIA DE EDAD
}

\section{Elizabeth Herrera Lozada? \\ Sergio Quitión ${ }^{2}$}

\section{Presentación}

El presente texto es resultado de los desarrollos curriculares y académicos propuestos por la universidad, primeramente a manera de ponencia en torno al análisis de autores de filosofía moderna, y posteriormente presentado en el I Congreso Internacional de Humanidades de la Universidad Santo Tomás. Surgió luego una reconstrucción mediante el diálogo entre ambos autores, partiendo de un análisis sobre las cuestiones y discursos del filósofo Emmanuel Kant, centrándose principalmente en sus ideas pedagógicas desarrolladas en el Tratado de Pedagogía de 1803 que a su vez complementa las cuestiones sobre la importancia de la facultad de filosofía desarrolladas en el texto El conflicto de las facultades de 1794, pues aquí la filosofía será la juez y la mediadora de los discursos académicos y científicos que las demás facultades, como medicina y derecho proponen dentro de la sociedad, pensando entonces a la pedagogía como la primera incentivadora de un discurso filosófico y por ende crítico y reflexivo en el sujeto.

Este encuentro de la pedagogía como medio en la correcta formación del individuo, y la filosofía como facultad crítica y examinadora de los discursos educativos dentro de la sociedad colombiana, permiten como se ha dicho, que surja este diálogo con miras a su realización práctica, proyectándose una mejor educación para el mañana, gracias a un ejercicio serio y reflexivo de la razón, donde confluyen estas dos materias que, en voz del filósofo Emmanuel Kant, aportan por una apuesta al sentido práctico de las actividades universitarias y por ende sociales, recordando el papel de la filosofía y de la educación como disciplinas intrínsecas para una sana sociedad que el hombre no debe olvidar.

1 Egresada en proceso de grado de la Licenciatura en Filosofía y Lengua Castellana de la Universidad Santo Tomás. Perteneciente al semillero Enkantados: Kant y nosotros. isaherrelozada@gmail.com

2 Licenciado en Filosofía y Lengua Castellana de la Universidad Santo Tomás. Perteneciente al semillero Enkantados: Kant y nosotros. 
La mente no es un recipiente que tenga que llenarse, sino un fuego que tiene que encenderse.

Plutarco

Con inspiración en el pensamiento educativo de Immanuel Kant, el artículo indaga por los aportes de las humanidades a la formación ciudadana en la educación superior. En la primera parte, (I) se expone la propuesta educativa de Kant recogida en su Tratado de pedagogía, con énfasis en la idea de una "educación para el mañana", que no es más que una educación que busca fomentar un pensar autónomo y libre en el sujeto, pensado a partir de un desarrollo y mejoramiento constante de su formación, para salir poco a poco de la "minoría de edad", y llegar a valerse por sí mismo, en un uso adecuado del conocimiento. Dichos principios pedagógicos inspirados por Kant permitirán en el segundo apartado (II) un examen de los estamentos sociales que fundamentan la educación superior, "a la izquierda del parlamento universitario", como instancia crítica que logre promover el uso público de la razón entre los estudiantes de las universidades colombianas, sugiriendo un mejoramiento en la calidad educativa, que cuestione y comprenda el verdadero papel que cumplen las universidades en la sociedad colombiana.

Con el fin de establecer la comprensión Kantiana sobre la educación, se debe inicialmente reconocer las condiciones para que germine el valor del principio educativo, que parte de conocimientos superiores que la razón misma tiene por naturaleza. El principio educativo es pues llegar a un fin natural, como lo expone Kant en su tratado de pedagogía de 1803:

La educación es un arte, cuya práctica ha de ser perfeccionada por muchas generaciones. Cada generación, provista de los conocimientos de las anteriores, puede realizar constantemente una educación que desenvuelva de un modo proporcional y conforme a un fin, todas las disposiciones naturales del hombre, y conducir así toda la especie humana a su destino. La providencia ha querido que el hombre deba sacar el bien de sí mismo y le habló, por decirlo así: « ¡Entra en el mundo!; yo te he provisto de todas las disposiciones para el bien. A ti te toca desenvolverlas, y por lo tanto, depende de ti mismo tu propia dicha y desgracia». (Kant, 1983, p. 34)

Es bien cierto el dicho que dice "La ignorancia es la raíz de todos los males". El

3 Afirma el filósofo en el texto, Respuesta a la pregunta ¿Qué es la ilustración? Lo siguiente: La minoría de edad significa la incapacidad de servirse de su propio entendimiento sin la guía de otro. 


\title{
Escenarios de la formación investigativa
}

hombre, al no valorar su razón y al desconocer la dimensión de sus capacidades cognitivas, derrocha y desaprovecha sus facultades, haciendo por ello un inadecuado uso de su libertad, convirtiéndolo, en términos de Kant, en un ser bárbaro, en un animal. Admito, que aquí mi tema recuerda la consideración del sensato Hiperión cuando afirmaba: "realmente me parecía a veces, cuando me encontraba entre aquellas gentes cultivadas, que la naturaleza humana se había disuelto en la enorme diversidad del reino animal" (Hörderlin, 1976, p. 42). Pues bien, un posible escape a esto, se puede lograr desde, una comprensión del necesario uso de la razón que lleve a reconocer el valor de la existencia, como la unidad que configura el todo, actuando así para un mismo fin, como Kant lo afirma:

\begin{abstract}
Con la educación actual no alcanza el hombre por completo el fin de su existencia; porque, ique diferentemente viven los hombres! Solo puede haber uniformidad entre ellos, cuando obren por los mismos principios, y estos principios lleguen a serles otra naturaleza. Nosotros podemos trabajar en el plan de una educación conforme a un fin y entregar a la posteridad una orientación que poco a poco pueda realizar. Las orejas de oso, por ejemplo, cuando se las trasplanta, tienen todas el mismo color; al contrario, cuando se siembran, se obtienen colores diferentes. La Naturaleza, por tanto, ha puesto en ellas los gérmenes, y basta para desarrollarlas, su siembra y trasplante convenientes. Lo mismo sucede con el hombre. (Kant, 1983, p. 34)
\end{abstract}

Kant nombra unos principios que unifican la existencia, y que los debe buscar la humanidad. Tales principios abarcan los usos supremos de la razón, como el pensar autónomo del sujeto - el pensar por sí mismo-, afirmando de ello que "[...] La razón humana revela verdadera causalidad, donde las ideas se tornan causas eficientes (de los actos y de sus objetos), es decir en lo moral, sino incluso en relación con la naturaleza misma" (Kant, 1983, p. 312). Así, al lograr un carácter moral autentico del sujeto, que lo conduzca a actuar según la máxima universal de "cumplir el deber por el deber mismo", se genera, "Un valor elevado del carácter: hacer el bien no por inclinación sino por deber" (Kant, 1961, p. 74). Formando al hombre como un ser altruista, responsable y consiente de la existencia. Se manifiesta entonces, la ley universal de la necesaria unidad para el bien de la especie y su desarrollo constante a la perfección, cumpliéndose así la máxima Kantiana que indica: "No debo proceder nunca sin de forma que pueda también querer que mi máxima haya de convertirse en ley general" (Kant, 1961, p. 80).

La ley general es vivir en la unidad existente, en la medida en que me reconozco con el otro. En este reconocimiento está el impulso y la necesidad de desarrollar las facultades humanas para el bien, como afirma Kant: "El hombre debe desarrollar sus disposiciones para el bien; la providencia no las ha puesto en él ya formadas, son meras disposiciones y sin la distinción de moralidad" (1961, p. 
34). En la disposición del hombre está desarrollar sus facultades, por lo tanto, la voluntad debe actuar según su principio formal ${ }^{4}$, que surge de un examen crítico y elaborado del ejercicio de la razón como facultad suprema, encontrando así su incorruptible valor: "Mediante su cultivo, la razón es que reconoce su más alto designio práctico en la creación de una voluntad buena" (Kant, 1961, p. 70). Así, los frutos del adecuado uso de la razón son las manifestaciones prácticas de una buena voluntad, que formen un carácter autónomo y libre en el sujeto.

En suma, reconocemos que el valor trascendental de la razón está en que "de sus frutos hablará la práctica" y según Kant, estos deben ser de alto contenido moral, necesarios e intrínsecos en la existencia y por ende indiscutibles. Sobre esto descubro dos cosas: Que la razón debe ser cultivada; y que de este cultivo se debe encargar la educación. Ahora bien, tal acción (la de cultivar la razón) no es desarrollada arbitrariamente por cualquier ente, pues la educación es un arte y a la vez, según Kant, "el problema más grande y difícil que puede ser propuesto al hombre" debido a que requiere del genio creador, y su fervoroso compromiso para forjar una bella obra. Este sujeto es el principal responsable de transformar las generaciones a estados más perfectos, pues tiene el poder del cuidado, y el don de instruir: hablo de las madres y los maestros.

La madre debe ser el primer vínculo del niño para conocer el mundo, la primera edificadora del pensamiento autónomo y libre del pequeño, debe ser la primera que reconozca y fructifique desde su formación las facultades que tanto hemos nombrado en este discurso. Para ello, desde los primeros cuidados, se implementan acciones significativas que repercutirán en el constante desarrollo del niño, desde su fortaleza en el cuerpo, empezando por ello a eliminar costumbres que disfrazan desde la cuna del infante sus potencias naturales, como por ejemplo, emplear los ordinarios andadores para que el niño aprenda a caminar, esto lo aborrece Kant: "Es chocante que se quiera enseñar a andar a un niño; como si un hombre no pudiera andar por falta de instrucción" (1961, p. 52). Por lo tanto, para Kant "es una educación negativa emplear instrumentos allí donde el niño los tiene naturales $[\ldots]$ y cuantos más instrumentos artificiales se usen, tanto más dependerá el hombre de ellos" (p. 53). Por consiguiente, la madre debe ser la primera que influya en el niño un pensamiento íntegro, que reconozca en la propia naturaleza, el desarrollo ordenado de sus facultades, "no haciéndole todo" ni evadiendo su crecimiento natural. Al lado de ello, Kant en otra expresión concluye, el mensaje de Confucio: "educa a tu hijo con un poco de hambre y un poco de frio", cuando nos exhorta a no satisfacer todos los caprichos en la primera juventud pues "se pervierte su corazón y sus costumbres", exhortando a los padres a una educación dura, que fortalezca el cuerpo y el alma:

4 Separado de toda realidad empírica, para su veracidad. 


\title{
Escenarios de la formación investigativa
}

Muchos padres quieren acostumbrar a sus hijos a todo [...] Quieren por ejemplo, que puedan dormir y levantarse a cualquier hora o que coman cuando ellos lo exijan $[\ldots]$.

Una cama dura es mucho más sana que una blanda. Generalmente, una educación dura sirve mucho para el fortalecimiento del cuerpo. Entendemos por educación dura el mero impedimento de la comodidad. (Kant, 1961, p. 46)

Desde los principios kantianos ya reconocemos algunos valores formativos que tiene la madre en la primera infancia, para forjar desde el niño una inclinación hacia el pensamiento propio y libre, siendo casi un compromiso "acostumbrar al hombre desde temprano a someterse a los preceptos de la razón".

Ahora, durante el desarrollo del niño, el vínculo materno por necesidad se va superando (recordemos la génesis de la estructura), incitando a círculos formativos más complejos, que se establecen en la escuela. En este espacio formativo, hablamos del agente encargado del segundo paso en la formación: la instrucción y la dirección. Estas, según Kant, pertenecen al componente positivo de la educación que supera una mera disciplina y el absurdo régimen de reprimir faltas o errores. Desde ambas posiciones nace la diferencia entre el instructor (Informator), que es simplemente un profesor, y el ayo (Hofmeister), que Kant lo llama un director, y afirma que "aquel educa solo para la escuela, este, para la vida" (1961, p. 41). El ayo que educa para la vida es el guardián del conocimiento que despierta en los niños el fuego de la búsqueda incesante, y que por ende le da un valor verdadero al movimiento natural y perfecto de las facultades, como herramientas para conocer. Él es genio, que tiene el poder de cultivar el conocimiento, por medio de su adecuada instrucción, él desarrolla el conocimiento, en la medida en que permite y fortifica el pensar autónomo en sus alumnos. De esto, Kant afirma:

\begin{abstract}
Al hombre se le puede adiestrar, amaestrar, instruir mecánicamente o realmente ilustrarle. Se adiestra a los caballos, a los perros, y también se puede adiestrar a los hombres. Sin embargo, no basta con el adiestramiento; lo que importa sobre todo, es que el niño aprenda a pensar. Que obre por principios, de los cuales se origina toda acción. Se ve, pues lo mucho que necesita hacer una verdadera educación. (1961, p. 33)
\end{abstract}

En efecto, esto genera una oposición evidente con teorías como el conductismo de Iván Pavlov, pues no somos simples máquinas estimulantes que responden a un medio (como los animales) ${ }^{5}$, sino seres pensantes y razonables con capacidad de construir conocimiento, y a partir de ello, obrar por principios supremos.

Aquí nos preguntamos: ¿este papel de fortificar el pensamiento autónomo y

5 No se pretende con esto menospreciar el valor de la existencia animal. 
libre en el sujeto lo está cumpliendo la pedagogía actual? ¿Existen ayos en la praxis educativa? Sabemos que muchas reformas pedagógicas han surgido como un posible acercamiento a esto, queriendo implementar no sin más, métodos para un desarrollo íntegro del sujeto, teorías como los centros de interés de Decroly, la escuela para hombres de Pestalozzi, son ejemplos de ello. Pero como dije inicialmente, la teoría pedagógica que sostiene este dialogo entre Kant y Piaget es el constructivismo, pues este, más que una teoría es una actitud que debe tener el maestro, dirigida para que el alumno aprenda. Es la orientación y la instrucción del ayo aplicadas a una constante construcción de conocimiento, basado en los intereses, las necesidades, y sobre todo a la estructura afectiva y cognoscitiva del alumno. Entonces, según Ganem y Ragasol "lo que han hecho los teóricos es intentar descifrar la forma en que el sujeto aprende, y eso los maestros lo traducen de manera cotidiana en estrategias concretas" (2010, p. 11). Estas estrategias concretas deben basarse en una comprensión de la compleja integridad que constituye al ser humano. Para el maestro constructivista, "no hay respuestas incorrectas, ya que la perspectiva del maestro cambia: "No es que el alumno no entienda, no es que el alumno sea malo, no es que no quiera aprender, lo que en realidad sucede es que se le está dificultando manejar el estímulo que se le propone porque no es adecuado, no es para su edad, o no tiene vinculación con él" (Ganem y Ragasol, 2010, p. 53). La creatividad del maestro debe estar ligada a un interés de que el alumno conozca y aprenda construyendo conocimientos; así, por ejemplo, al tomar un ejercicio matemático aparentemente mecánico, $1498 \div 4.2$, "lo transforma en acertijos matemáticos que signifiquen algo real y tangible para el alumno, por ejemplo, 'si tengo 1498 litros de agua y en la tienda venden botellas con 4.2 litros de capacidad, ¿Cuántas botellas serán necesarias para contener el agua?” (p. 13). Así, y con otras pequeñas situaciones de aprendizaje en la escuela se puede lograr que "el alumno logre apropiarse de los contenidos relevantes del programa y utilizarlos en situaciones vinculadas en su vida" (p.13).

Desde los principios kantianos le he dado un valor trascendente a la educación, concibiéndola como el puente que conducirá a la raza humana a la perfección, aceptando así la posibilidad que tiene el hombre para llegar a la perfección. Por lo tanto, y como he insistido: solo cuando el hombre se reconozca como una ser pensante, manejará su libertad a tal nivel que actuará según la máxima Kantiana: Cumplir el deber por el deber mismo. Las ideas de este discurso concernientes a los fines de la educación (pues nadie, pienso, censurará lo concerniente a la explicación epistemológica y filosófica), por más utópicas e irrealizables que puedan resultar, no se desvanecen como posibilidad en la mente humana, pues si bien, Kant lo ha dicho: "la idea de una educación que desenvuelva en los hombres todas sus disposiciones naturales, es sin duda verdadera" (citado en Ganem y Ragasol, 2010, p. 33), pues es más natural soñarlo, que darlo por imposible. 


\section{Escenarios de la formación investigativa}

Creo que aquí se ve bastante bien cómo a partir de unos esbozados planteamientos de lo que Kant reconoce como la médula de la educación, se evidencia su ambición de postular a un hombre libre y autónomo.Concibo pues, la piedra angular por la cual se fomentará esa educación humanística, y por la cual se nos es posible pensar en la necesidad que surge de educar para un mejor mañana; es este breve consejo, lo que manifiesta la sustancia de todo lo que hemos querido decir, y lo que resume nuestra intención de querer hablar de una educación para el mañana, que solo en palabras de Kant podemos expresar:

Un principio del arte de la educación, que en particular debían tener presente los hombres que hacen sus planes es que no se debe educar a los niños conforme al presente, sino conforme a un estado mejor, posible en lo futuro, de la especie humana; es decir, conforme a la idea de humanidad y de su completo destino. Este principio es de la mayor importancia. (Kant, 1983)

Pensar en esta idea educativa solo es posible si la precede una idea universal y esperanzadora del hombre; una idea que traspase sus propias falencias e invoque lo más perfecto, que invoque eso -como dice Kant-, de lo cual nos dotó la providencia. Solo creyendo en nuestras propias capacidades, y solo al darle vida a esa perfección que está en potencia, podemos pensar en una educación para el mañana.

Invocar la posibilidad de una educación para el mañana conduce necesariamente a la crítica de la presente pedagogía, que nos lanza al fluctuante debate sobre las debidas políticas institucionales de las universidades colombianas. Hallándonos inmersos en una disputa mediática que, al parecer, se olvidaba de la relación vinculante entre el saber y un proceso crítico que dictamine su ascenso. Las campañas cientificistas que, encumbradas sobre el ideario del progreso, piensan liderar los procesos académicos se han restringido a la proliferación de políticas de crecimiento y cultivo deslegitimando un rectorado crítico que pueda encausar su curso. La meta ha subestimado el valor del camino. Frente a esta problemática del saber que se autolegitima, y que pretende universalizar el criterio del porvenir sacrificando los presupuestos de la crítica, preguntémonos por el papel de la filosofía en la academia, cuestionando no solo su labor específica de investigación, sino ante todo su servicio a los saberes externos a ella en términos de conciencia crítica. La posibilidad de esbozar, apoyados en Kant, la necesidad de la existencia de la facultad de filosofía en la universidad, derivará, precisamente, en la justificación de aquélla como conciencia crítica, que no alejado de su legado pedagógico, será conductora ecuánime de las empresas científicas de la cultura, hacia su perfeccionamiento ulterior. 
Kant fue víctima de la censura. Bajo la figura de edictos restrictivos, su obra La religión dentro de los límites de la mera razón hubo de ser opacada por la fuerza coercitiva del poder gubernamental prusiano. Y aunque años más tarde se le devolvió a Kant la libertad de publicación, aquella misiva prohibitiva de Federico Guillermo, que tildaba su trabajo filosófico de "corruptor", exacerbó la necesidad de exponer, filosóficamente, el valor de la crítica y su menesterosa presencia en los movimientos académicos de la universidad pro-ilustrada. Bajo este clima de sedición, Kant recoge tres trabajos en torno a un presunto conflicto entre saberes estatutarios y un saber crítico libre. Es así que nace El conflicto de las facultades, texto que recrea los avatares de la relación entre, por un lado, la teología, el derecho y la medicina y, por otro, la filosofía. No quiere decir esto que Kant oponía taxativamente el trabajo filosófico al de las nombradas disciplinas, sino que, de hecho, consideraba que los límites de aquellas están dados por la fundamentación racional de la primera. Es la filosofía, en esta medida, un contrapeso a la ciencia del teólogo, del jurista y del médico que, entregada a su ciego cultivo, amerita la dirección y el control por parte de una esfera libre y desinteresada que pueda aclarar el sendero que pretende atravesar.

La universidad, para Kant, se encuentra constituida por tres facultades de orden superior y una de orden inferior. Las facultades superiores son la teológica, la jurídica y la médica, mientras que la inferior es la filosófica. El interés de las primeras es puramente científico, es decir, un propósito unilateral al descubrimiento de la verdad en pos del servicio a determinados destinatarios en el orden técnico. Es así que, tanto el teólogo bíblico, como el jurista y el médico, atienden a un cultivo de los modos instrumentales en que es aplicable su saber. En el caso del teólogo bíblico, su ciencia estará al servicio de una función social redentora en vistas a la salvación del pueblo, del mismo modo que el jurista garantiza la legitimidad de la propiedad privada y el médico procura recetas para la buena salud. El filósofo no tiene aquella utilidad directa, su labor no se restringe a las aplicaciones empíricas de la ciencia, ni a las fórmulas beneméritas para la materialización de un saber.

Los representantes de las facultades superiores se hallan sublimados en virtud del poder conferido por el Estado gobernador. Aquellos se toman a sí mismos como maestros del pueblo que dictaminan principios correspondientes a las inclinaciones naturales de sus receptores. De este modo, serán escuchados y valorados por el pueblo como eruditos de la bienaventuranza, la justicia y la salud, y proclamados como los poseedores de la verdad y la sabiduría. Por su parte, la facultad de filosofía se entrega a una labor cuanto más noble menos notoria y estimada, pues, ante el poder retórico y dominante de los sabios de las facultades superiores, ejerce una función crítica que somete a juicio los saberes considerados incuestionables por las facultades superiores. La facultad de filosofía es la jueza de 


\section{Escenarios de la formación investigativa}

los estrados de la razón, razón misma que provoca en el hombre un pensamiento propio, por medio de una educación con sentido de autonomía.

De cara a la masiva adhesión del pueblo a los dictámenes de los sabios, la facultad de filosofía desmiente aquella "fuerza mágica" -al decir de Kant- que se le es conferida taxativamente, y confía la batalla a la razón, donde es ésta el único criterio válido para legitimar las prácticas y los saberes. En esta función crítica radica el mentado conflicto de las facultades, donde las máximas engalanadas de las facultades superiores entran en litigio en medio de un examen público de sus doctrinas. De este modo, es necesario que la facultad de filosofía esté dotada de suprema libertad y, al tiempo, se halle necesariamente abocada al examen, como su máxima obligación, cuyo medio en este caso ha de fundamentar el fin educativo, como posibilitador del examen y la crítica, de los saberes y las prácticas sociales. Esto recala en un pugna que puede ser, dice Kant, ilegítima o legítima. Es ilegítima cuando el poder de las facultades superiores se impone por demás sobre el criterio del pueblo, cuando la fuerza crítica se ve acallada por el gobierno, o cuando los argumentos litigantes obedecen a conjeturas subjetivas o a amenazas desaforadas. Por el contrario, la pugna legítima entre las facultades es aquella donde la batalla permanece en el escenario público en pos de descubrir la verdad. En esta medida, el poder de las facultades superiores no se impondrá sobre la inferior, sino que, bajo la forma de dos aguerridos caballeros, se mantendrán alertas en la disputa hasta que se logre un acuerdo imparcial en aras del progreso común.

Es así que ante el conflicto, la facultad de filosofía no puede entregarse a la blandura ni el escozor, pues su fuerza gravita justamente en permanecer vigilante y solícita "la facultad de Filosofía no puede dejar de blandir sus armas contra el peligro con que se ve amenazada la verdad, cuya custodia le ha sido encomendada, habida cuenta de que las facultades superiores nunca renunciarán a su afán de dominio" (Kant, Ak.VII, 33/p. 747). De este modo no puede dejarse sobornar de las circunstancias del litigio, o entregarse amistosamente a resoluciones que comprometen su búsqueda perenne. No quiere decir ello, empero, que el litigo provea a la facultad de filosofía de un poder exacerbado para imprecar los dogmas o los principios de sus contrincantes, o más lejos aún, para poner en duda u ofender el poder del Estado que está detrás de éstas, ya que, la posición de la facultad inferior es académica, esto es, reservada a los problemas de la ciencia y del saber en búsqueda del esclarecimiento y la verdad. De este modo, dice Kant, el conflicto entre las facultades litigantes ha de perdurar hasta que un acuerdo, en ambas instancias equilibrado, permita que la comunidad académica y civil se orienten hacia el progreso, esto es, un perfeccionamiento de su saber junto a la abolición de cualquier restricción del gobierno frente a la libertad de la crítica.

Es en esta medida que identificamos la existencia de la facultad de filosofía dentro del ambiente universitario como necesaria, puesto que, de un lado controla 
las envestidas académicas de las facultades superiores y, de otro, les sirve como refuerzo en la aclaración del objeto de examen y crítica. A la facultad de filosofía, entonces, ha de serle connatural el carácter de libertad con el cual le es lícito encontrar la verdad en provecho de todas las ciencias. Si se mira de esta manera, encontramos que, al parecer, la facultad de filosofía se mantendría en guardia frente a los discursos gubernamentales filtrados en las facultades superiores, aún en detrimento de su pura inclinación desinteresada. A este respecto, la facultad de filosofía no se consolida exclusivamente como afrenta a cualquier poder gubernamental, sino que, de hecho, puede servir de asesora a quien tenga dicho poder, siguiendo fielmente los fines de la razón en correspondencia con los fines de la autoridad. La facultad de filosofía sería en esta medida una entidad directriz del público letrado.

Frente al carácter privativo en el uso de la razón que mantienen las facultades superiores apoyadas en estatutos y parámetros inspirados por la autoridad, la facultad de filosofía, libre de cánones preceptivos, puede examinar libremente los progresos de la ciencia, apoyando con ello el desarrollo de la misma. De esta manera, la facultad de filosofía permite aclarar el objeto de los demás saberes en tanto que su propio objeto es indefinido e ilimitado. De la independencia intelectual de la facultad filosófica no se sigue la oposición categórica a la norma, sino, ante todo, el examen y la búsqueda de sentido de ella. La polémica desatada entre los saberes, sin embargo, permite dilucidar que la administración del Estado opta por corromper el uso libre de la razón del filósofo, con lo cual, la concepción política del saber ha de entregarse al uso público garantizado en el ambiente académico, aquél donde funciona un "ente regulador". La filosofía puede, entonces, informar al gobierno sobre lo útil y perjudicial sin entregar su estamento crítico al influjo del poder dominante y coercitivo.

El conflicto entre las facultades se torna necesario si el progreso del saber es la meta y no el dominio político de las masas. Si se opta por tal tendencia al perfeccionamiento, de un lado, la balanza estaría apoyada por las campañas científicas de las facultades superiores, y de otro lado, se encontraría la facultad de filosofía como estamento crítico que promueve el uso público de la razón.

El funcionamiento crítico de la facultad de filosofía frente a las demás facultades se hace patente si revisamos las consideraciones kantianas en torno al conflicto. De un lado tenemos la confrontación entre el teólogo bíblico y un teólogo racional (filósofo-teólogo) en relación a las orientaciones interpretativas de los textos sagrados. Para Kant, el debido abordaje de la Biblia y de sus dogmas de fe ha de hallarse en función de la razón práctica, esto es, de la moralidad.

Para la firme creencia del teólogo bíblico, el estudio de las escrituras revelaría los misterios de la existencia humana, la creación y la divinidad que necesariamente han de alinear las convicciones de los creyentes como si, por efecto providen- 


\section{Escenarios de la formación investigativa}

cial, le fuese accesible la verdad. La fe en la revelación divina, como criterio de verdad, instaura una desperdigada devoción en un credo eclesiástico mesiánico apoyado en una presunta voluntad ajena. Por su parte, el filósofo que se enfrenta a las Escrituras lo hace con la consciencia de su oficio racional y con el seguro convencimiento de que su comprensión permite asumir los deberes morales cual mandatos divinos. En esta medida, las Escrituras no serían milagrosas revelaciones, ni verdades autoproclamadas, sino indicios de doctrinas morales que, halladas por medio del uso de la razón, delimitan un sentido direccional de los dogmas de cara al deber.

La exégesis de los textos, entonces, ha de abordarse, si no desde un horizonte netamente filosófico, sí en relación a principios dictados por la razón. El filósofo permite que las Sagradas Escrituras sean tomadas, no atendiendo a la pura literalidad a la que poco sentido práctico le es propio, sino ante todo por analogía, es decir, en función de la racionalidad moral que funciona de orientación hacia el deber de la naturaleza humana. Con ello, la facultad de filosofía se encausaría en el terreno de la pura religión, es decir, encaminada al obrar y no meramente en el creer, con lo cual el punto de vista práctico validaría la revelación en pro del mejoramiento moral del género humano "Solo entonces la interpretación es estrictamente auténtica, al convertirse Dios dentro de nosotros en el intérprete mismo" (Kant, Ak.VII, 48/p. 765). El enfrentamiento con las Escrituras por analogía a la moralidad alude a una interpretación a través de nuestro entendimiento y de nuestra razón atendiendo a los principios morales como mandamientos divinos, único camino fructífero en el enfrentamiento con los dogmas de fe. Es así que el texto bíblico no se comprendería en virtud de su valor dogmático, sino en función del mejoramiento de las costumbres.

En la misma proyección hacia el mejoramiento, Kant postula, centrado en el litigio con la facultad jurídica, la posibilidad de un curso continuo del género humano hacia lo mejor. Pensar en el detrimento de las costumbres en un continuo retroceso de la moralidad caería en una inminente reducción hacia la propia autoaniquilación. Superado este "terrorismo moral" y encontrando inviable la presuposición de un estancamiento perpetuo, se da por sentado que el género humano se halla en constante progreso hacia el mejoramiento con respecto a su destino moral. La confianza en un estado tal amerita una historia profética que, cimentada en datos de la experiencia, indique de un modo intemporal la tendencia hacia el progreso. El entusiasmo que despierta la posibilidad de la revolución de un pueblo pletórico manifiesta la disposición moral hacia el mejoramiento. Para la consolidación de una generación renovada, es precisa la garantía de libertad de un pueblo de no verse obstaculizado y, junto a ello, la meta de una constitución jurídica que, fundamentada moralmente, permita el establecimiento civil y político del progreso. 
El evento grandioso de la legislación proyectiva mantendría la firme convicción del progreso diagnosticado por la filosófica, con lo cual, la facultad jurídica habría de atender sus preocupaciones en función de una posible realización de la esperanza filosófica. De este modo, el progreso hacia lo mejor se erige como principio regulativo de los productos legales de acciones conformes al deber, donde no solo se presuponga el acatamiento a las leyes, sino también el cultivo y la educación de los hombres inspirada en la Ilustración de un pueblo. Solo con el acoplamiento de un proyecto filosófico enfocado en el progreso, y la idealización jurídica de una constitución para el dicho pueblo venidero, las facultades construirían un programa ilustrado como manifestación proyectiva en un inminente camino hacia el bien.

El médico y el filósofo se hallan en un diálogo más productivo. Mientras el primero se preocupa principalmente por el bienestar físico, el segundo se interesa por el provecho moral de sus acciones. Para Kant, es posible que las preceptivas de la medicina se vean enriquecidas por los lineamientos de un espíritu autoconsciente que, por medio de la costumbre y el sometimiento voluntario de sus sentimientos, fortalezca sus propios hábitos. El principio práctico de la moralidad, entonces, también habría de atender a lo físico, con lo cual el arte de prevenir enfermedades se consolida, al mismo tiempo, como la forma de dominar los sentimientos enfermizos por medio del firme propósito de la voluntad. Una dietética tal, sugerida por la medicina, se hallaría en consonancia con un estoicismo moral que determinaría los hábitos saludables del cuerpo (el comer y el beber mesuradamente, el tiempo preciso en el descanso, etc.) en correspondencia con el forjamiento de un espíritu autorregulador que, del mismo como la salud se preocupa por el cuerpo, alude al compromiso del pensamiento en relación al dominio de los sentimientos y de las pasiones. 


\section{A manera de conclusión}

Las reflexiones kantianas en torno a la pedagogía, indican la importancia que como educadores se ha de tener para un desarrollo verdaderamente integral de todas las dimensiones que acompañan al ser humano, que se van modificando desde su nacimiento hasta su adultez, insinuando una preparación para su entrada al mundo académico, preparándolo como un sujeto activo en la crítica y la reflexión, ejercicios esenciales de la filosofía; esto conlleva pues al examen del conflicto de las facultades, pues nos sugieren un concepto crítico de participación de la filosofía en las demás esferas del saber. Su labor tiene una función no solo académica, sino también política, puesto que sirve de juez y al mismo tiempo de consciencia ante el progreso y el mejoramiento moral de las prácticas y del saber. La academia no puede, en modo alguno, entregarse a la voluntad ajena de las facultades superiores, puesto que sacrificaría la necesaria conducción del examen. Y cuando decimos facultad filosófica, entendemos las humanidades en su integridad, aquellas que preocupadas por el hombre, la civilización y la cultura, propician el análisis del saber científico y su funcionalidad en la sociedad. Solo si el conocimiento y el saber cultivado por las disciplinas se encuentran regulados académicamente bajo una educación que piense en el mañana, se proyecta el camino hacia la Ilustración, donde la libertad y la autonomía son los principios de su curso. Es de esta manera que las ciencias humanas y sociales, principalmente la educación, se configuran como las redentoras del uso público de la razón, no restringidas a la exclusiva y privativa aplicación del saber, sino ante todo al servicio crítico y a la contrapartida ante la censura. Si interpretamos El conflicto de las facultades como un desafío a la censura, a los discursos y los poderes coercitivos del saber dominante, hemos de asumir, del mismo modo, la necesidad y la vigencia de las ciencias humanas en la universidad como las representaciones del "ala izquierda del parlamento universitario", como las fuerzas críticas que inquietan la pasividad de los receptores estudiantiles y promueven el uso público de la razón, el juicio crítico de las políticas gubernamentales, y el propio cultivo de la educación superior. 


\section{Referencias}

Ganem, P. y Ragasol, M. (2010). Piaget y Vygotski en el aula: el constructivismo como alternativa de trabajo docente. México: Editorial Limusa.

Hörderlin, F. (1976). Hiperón o el eremita en Grecia. Madrid: Libros Hiperión.

Kant. (1961). Cimentación para la metafísica de las costumbres. Buenos Aires: Librería Aguilar .

Kant, I. (1983). Pedagogía. Madrid: Akal.

Kant. (1998). Critica de la Raźón pura. Madrid: Editorial Santillana.

Piaget, J. (1985). Seis estudios de Psicología. Barcelona: Editorial Planeta DeAgostini. 